\title{
Religião e fecundidade: uma análise do nível e padrão de fecundidade segundo grupos religiosos no Brasil em 2006.
} Religion and fertility: a analysis of fertility level and pattern by religion group in Brazil in 2006.

\begin{abstract}
Resumo
Os estudos sobre a associação de fenômenos demográficos e religião têm mostrado que as instituições religiosas e a identidade religiosa dos indivíduos podem influenciar de várias maneiras o comportamento demográfico dos seguidores. Objetivou-se identificar e analisar os possíveis diferenciais no comportamento de fecundidade segundo religiões entre as mulheres de 15 a 49 anos no Brasil, incluindo análises a partir da conversão e frequência a cultos e cerimônias religiosas. Para isso foram utilisados os dados da Pesquisa Nacional de Demografia e Saúde da Mulher e da Criança de 2006. Os resultados sugerem que realmente existem diferenças nas taxas de fecundidade segundo religiões, sendo que esses diferenciais também são verificados para aquelas mulheres que foram criadas sempre em uma mesma religião e para aquelas que mudaram de religião ao longo de seu período reprodutivo e também há diferenciais importantes nos níveis e padrão de fecundidade quanto à frequência na participação de cultos e cerimônias religiosas.
\end{abstract}

Palavras-Chave: afiliação religiosa; número de filhos; conversão; frequência a cultos e cerimônias religiosas.

\begin{abstract}
Studies on the association of demographic phenomena and religion have shown that religious institutions and religious identity of individuals can influence in various ways the demographic behavior of followers. This study aimed to identify and analyze possible differences in the fertility behavior and accordance religions among women between 15-49 years old in Brazil, including analyzes from the conversion and the frequency in religious worship and ceremonies. For this data from the National Survey of Demography and Health of Women and Children (DHS) of 2006 were used. The results suggest that there are differences in fertility rates and types of religions. The same are also observed for those women who were always had the same religion and that changed religion throughout their reproductive period and there are also important differences on the fertility levels and pattern by participation in religious worship and ceremonies.
\end{abstract}

Keywords: religious affiliation; number of children; conversion; attendance at religious services and ceremonies.

\footnotetext{
Artigo submetido em 03 out. de 2014 e aprovado em 09 dez. 2014.

* Doutora em Demografia pelo CEDEPLAR/UFMG, pesquisadora e professora da ENCE/IBGE. País de origem: Brasil. E-mail: litaacarvalho@yahoo.com.br

** Doutora em Sociologia/Demografia pela Universidade do Texas (2010) e mestre em Demografia (2004) pela UFMG. Professora adjunta do departamento de Demografia e pesquisadora do CEDEPLAR/UFMG desde 2012. País de origem: Brasil. E-mail: anapaulaverona@gmail.com
} 


\section{Introdução}

O comportamento da fecundidade tem sofrido grandes mudanças em todo o mundo, em que há uma tendência geral de redução do número de filhos por mulher. Os países desenvolvidos, especialmente os países europeus, têm demonstrado um cenário de persistentes taxas muito baixas de fecundidade. Não diferente deste contexto e seguindo um caminho muito parecido, contudo em um processo muito mais rápido, muitos países da América Latina, especialmente o Brasil, têm se destacado pelo seu acelerado processo de transição da fecundidade, com suas Taxas de Fecundidade Total (TFT) bastante declinantes nos últimos 40 anos. Segundo os Censos do IBGE, a TFT era 6,3 filhos por mulher em 1960, passando para 4,4 em 1980, 2,4 em 2000, ficando abaixo no nível de reposição a partir de 2004, em que a tendência de queda permaneceu, em que em 2010 a TFT ficou de 1,86 filhos por mulher.

Apesar da queda generalizada da fecundidade, observa-se grandes diferenciais segundo algumas características socioeconômicas e demográficas das mulheres. O estudo de Berquó, Cavenaghi (2004) mostrou a importância de se controlar a fecundidade segundo escolaridade, renda e raça/cor das mulheres. $\mathrm{O}$ estudo revelou que controlando categorias de anos de estudo e rendimento médio familiar per capita, no Brasil, em 2000 42\% das mulheres já se encontravam sob um regime de fecundidade abaixo do nível de reposição. $\mathrm{O}$ estudo também revelou que as mudanças na fecundidade ocorreram tanto no nível quanto no padrão de distribuição dos nascimentos, em que houve nos últimos anos uma tendência de rejuvenescimento da fecundidade, com aumento significativo da contribuição dos grupos de idade entre 15 a 24 anos. Essa tendência foi observada desde os anos 1980 até a década de 2000. Já em 2010, os dados mostraram uma pequena redução da fecundidade no grupo de 15 a 19.

Muitos estudiosos buscaram entender essas rápidas mudanças no comportamento reprodutivo das mulheres com a contínua redução da fecundidade. 
Especialmente nos estudos demográficos, muitas teorias foram criadas a fim de explicar o declínio da fecundidade (Alves, 1994). Alguns autores (Hammel, 1990) discutem a importância de alguns atributos culturais, tais como a religião, língua falada e o papel das redes para as mudanças na fecundidade. Especialmente, sobre o papel da religião, os estudos sobre a associação de fenômenos demográficos e religião têm sido substancialmente desenvolvidos ao longo das últimas três décadas, contudo são quase que exclusivamente realizado nos Estados Unidos e na Europa. Estes estudos têm mostrado que as instituições religiosas e a identidade religiosa dos indivíduos podem influenciar de várias maneiras o comportamento demográfico dos seguidores, seja via mortalidade e saúde (Ellison, Levin, 1998; Verona et al., 2010), migração (Hirschanm, 2004; Levitt, 2003) ou fecundidade e comportamento sexual (Mcquillan, 2004; Goldscheider; Mosher, 1991; Heilborn et al, 2005).

No Brasil, pesquisas sobre comportamento demográfico e religião ainda são poucas (Machado, 1994; Wood et al., 2007; Verona, 2010; Zanata, 2011), especificamente quanto à influência da religião e religiosidade na fecundidade e nas preferências reprodutivas dos fiéis. Os estudos existentes no Brasil sobre esse tema, na maioria deles se concentram no comportamento de adolescentes (Gupta; Leite, 1999; Mckinnon et al. 2008; Miranda-ribeiro et al, 2009; Verona; DiasJunior, 2012) e estes revelam que a religião, conjuntamente a outras variáveis, pode ter um papel importante para o início da vida reprodutiva. Não foram encontrados estudos que investigaram os diferenciais de fecundidade entre as mulheres adultas ao longo de todo o período reprodutivo.

O interesse em estudar a relação entre fecundidade e religião, se dá também pelo fato de que o Brasil tem passado por mudanças importantes no seu panorama religioso. Verona (2011) afirma que tem ocorrido uma diminuição do número de católicos em decorrência do aumento do número de protestantes nas últimas décadas (ALves; Novellino, 2006; Antoniazzi, 2006). A autora destaca a necessidade de que os demógrafos brasileiros comecem a analisar mais profundamente a associação entre a religião e os componentes demográficos. 
Devido a importância dessas informações para o atual contexto brasileiro de baixa fecundidade e numa tentativa de contribuir para o desenvolvimento deste tema no país, as perguntas orientadoras deste estudo foram: Qual é o nível e o padrão de fecundidade segundo os grupo religiosos no Brasil? Há diferenças quando se analisa mulheres convertidas e não convertidas? E a frequência religiosa, interfere nos níveis e padrão de fecundidade das fiéis? Nesse sentindo o objetivo deste artigo foi descrever e analisar as Taxas Específicas de Fecundidade e a TFT segundo religião entre mulheres de 15 a 49 anos no Brasil em 2006, identificando possíveis diferenciais a partir da análise de conversão e frequência à cultos e cerimônias religiosas.

Este artigo começa com uma breve exposição sobre as mudanças no panorama religioso religião no Brasil, os mecanismos de influência da religião sobre o comportamento reprodutivo e por fim expõe algumas considerações sobre os problemas metodológicos de se estudar a relação entre religião e fecundidade. No tópico seguinte, apresenta-se a base de dados e a metodologia utilizada para o cálculo das taxas. Na sessão posterior, tem-se a apresentação e discussão dos resultados e por último, são apresentadas algumas considerações finais.

\section{Revisão da Literatura}

O panorama religioso no Brasil passou por profundas transformações nas últimas décadas. Decol (1999) mostra que houve um “declínio do catolicismo, crescimento dos evangélicos, multiplicação das minorias, secularização e ascensão de um pluralismo religioso, diverso e multifacetado”.

Segundo Pieirucci, Prandi (2000) a religião no Brasil não está só passando por uma renovação, mas está assumindo formas que pareciam ser praticamente extintas. As religiões alternativas estão, cada vez mai,s invadindo a religião moderna, em que a magia e a intervenção sobrenatural parecem conquistar cada vez mais adeptos. Também Alves, Novelino (2006) mostram que o país, 
especialmente o Rio de Janeiro, tem experimentado mudanças tremendas em sua paisagem religiosa, com rredução na proporção de católicos (de 92\% para 74\%) e aumento entre os declarados evangélicos (de 5,2\% para 15,6\%).

Uma comparação feita entre os Censos de 1940 e 2000 pelo IBGE (2007) revelou que o Brasil era, pelas informações do censo de 1940, predominantemente católico. Dos 5,0\% restantes, os evangélicos contribuíram com a metade. Já em 2000 houve uma expressiva redução da população de católicos apostólicos romanos foi contrabalançada pelo crescimento de outros grupos, como dos sem religião, e as diversas religiões evangélicas que surgiram, principalmente as de origem pentecostal e neopentecostal. $\mathrm{O}$ incremento mais significativo foi observado para o grupo dos sem religião, que em 1940 não atingia o,5\% e, segundo o último censo, alcançou $7,4 \%$ do total de pessoas. Essa transição foi resultado da transformação da hegemonia quase absoluta do catolicismo para um país de pluralidade religiosa.

Alves (2012) acredita que haverá para as próximas décadas ainda um aumento expressivo do número de evangélicos, pois a população protestante tem maior proporção de mulheres, crianças e jovens (indicando maior fecundidade) e menor número de idosos ${ }^{1}$. O autor conclui que esta população estava atrasada no seu processo de transição da fecundidade em 2000, pois entre a população católica as mulheres de 0-49 anos de idade constituem 41,7\% das filiações, sendo que este número sobre para 46,9\% entre os evangélicos. Isto que dizer que a população evangélica tende a crescer em maior ritmo pois possuem mais mulheres em idade reprodutiva e mais meninas que vão entrar no período reprodutivo. Além disso, afirma que, somente pelo efeito da inércia demográfica, haverá crescimento da população protestante, e caso ainda ocorra uma diminuição de fiéis de outras denominações, o crescimento será ainda maior.

Essa persistente secularização tem levado à pouca atenção dada a religião nos últimos tempos, contudo, assim como defendido por Philipov, Berghammer

\footnotetext{
${ }^{1}$ Isso se justifica uma vez que a maioria dos fiéis deste grupo converteram a partir da década de 80, ou seja, a maior parte de sua população é recém-convertida.
} 
(2007), a ascensão dessas novas formas de religiões indica que a religião está longe de ser extinta, e independentemente de saber se estas representam um renascimento da religião ou se são apenas um estágio de secularização, há motivos suficientes para esperar que a religião ainda hoje tenha um impacto importante sobre o comportamento demográfico dos seguidores, e especialmente sobre a fecundidade. Para estes autores existem três deliberações pelas quais a religião pode ter influência sobre a fecundidade: importância do ensino religioso, o efeito do capital social e a função da religião em diminuir incertezas.

Marcum (1988) mostra que desde a segunda guerra mundial este tema já tem sido alvo de debates nos Estados Unidos, especialmente as tentativas de explicação dos diferenciais de fecundidade entre os protestantes, católicos e judeus. Explicações para tais diferenciais encontram grande influência da religião e se concentram em duas correntes: A primeira afirma que as diferenças na religião de cada grupo são as responsáveis pelos diferenciais de fecundidade, a segunda acredita que seriam as diferenças na distribuição das características sociais em todos os grupos religiosos que gerariam uma fecundidade diferencial. E assim a maior fecundidade entre os católicos estaria relacionada com as doutrinas da igreja em não restringir o nascimento, e por outro lado, a baixa fecundidade entre os judeus é atribuída aos altos níveis de educação e residência urbana desse grupo.

A importância de se estudar a relação entre fecundidade e religião se deve ao fato de que a religião possui normas de comportamento e diretrizes com relação a contracepção, às questões de gênero e vida familiar que influenciam direta e indiretamente os níveis e padrões de fecundidade dos casais. Além disso, o grupo religioso possui meios para comunicar estes ensinamentos aos seus membros e fazê-los cumpri-los, pois a religião possui um grande poder de coação, em que se oferece recompensas para aqueles que seguem os ensinamentos e punições para aqueles que não o fazem. Assim, quanto maior o apego e identificação dos membros à comunidade religiosa maior será a influência religiosa sobre a vida reprodutiva de seus seguidores, e consequentemente a influência da religião sobre 
a fecundidade das mulheres praticantes (McQuillan, 2004).

O estudo de Hayford, Morgan (2008) para os Estados Unidos mostrou que os diferenciais de fecundidade encontrados entre as religiões são parte de uma associação generalizada entre religiosidade e comportamento de família, ao invés de uma orientação especificamente pro natalistas associada a uma religião em particular. Neste estudo não se pôde determinar se é o conservadorismo religioso ou a família o principal fator causal por trás da associação, pois pode ser que para as mulheres em que a religião é mais importante elas desenvolvam atitudes mais conservadoras, ou que as mulheres com famílias mais tradicionais os valores são mais atraídos para a religião. Portanto, a associação conjunta entre a importância dos valores da religião, as intenções de fecundidade e tamanho da família reflete a ligação entre religião e família na construção da identidade pessoal.

McQuillan (2004) também chama a atenção para a ideia generalizada de que as religiões sejam pró-natalistas incentivando maior fecundidade de seus membros, contudo o autor demonstra que isso não é comum para todos os grupos religiosos e portanto não deve ser atribuído à todos os seguidores. Contrariamente, Philipov, Berghammer (2007) estudando 14 países europeus e a relação entre intenções reprodutivas, fecundidade e religião mostraram que na maioria dos países, as pessoas filiadas têm maior fecundidade idealizada e que as probabilidades são mais altas de intenção de ter outro filho e um maior número de esperado filhos que os não-filiados. A partir dos achados os autores se questionam: se a religião induz ideais mais elevados, intenções e número de filhos, então por que países com níveis mais altos de religiosidade, como Itália e Espanha, possuem os mais baixos níveis de fecundidade da Europa? Como resposta, eles colocam a inter-relação possível entre o declínio dramático na fecundidade e o declínio impressionante na frequência à igreja na Espanha. Outra justificativa seria o fato de que a religião como um sistema social inter-relaciona com outros sistemas sociais e essa interação pode reduzir o seu efeito sobre o comportamento da fecundidade.

Comparando dados da Espanha em 1985 e 1999 Adsera (2006a) mostrou que em 1985, o tamanho da família era semelhante para os católicos que 
participaram ativamente das atividades religiosas e aqueles que, embora nominalmente católicos, não eram participantes assíduos. Em 1999, o tamanho da família deste último foi inferior e comparável ao tamanho da família das pessoas sem filiação religiosa. Já os grupos de protestantes e muçulmanos tiveram a maior fecundidade. Em ourto estudo com 13 países desenvolvidos, a mesma autora conclui que número ideal de filhos é maior para os protestantes conservadores e católicos, afiliações com mais ensinamentos em prol da natalidade, do que para linha mais moderna de protestantes ou indivíduos sem filiação religiosa. A filiação religiosa, independentemente da religiosidade é mais significativa para explicar as diferenças no número ideal de filhos para os indivíduos mais velhos e para os homens do que para as mulheres. A autora ainda destaca que a perda de influência das instituições religiosas na sociedade, o grau de freqüência à igreja tornou-se um preditor mais saliente das normas de constituição de família, especialmente para as mulheres. Ser membro de igreja, independente da religiosidade, exerce maior influência nas preferências demográficas em sociedades pluralistas do que em países monopolizados por uma única filiação religiosa (Adsera, 2006b).

No estudo de Frejka, Westoff (2008) que tentou entender porque a fecundidade é maior em os EUA do que na Europa, revelou que as mulheres americanas são mais religiosas do que as mulheres europeias, medido especialmente através da participação em serviços religiosos e da importância atribuída à religião na vida diária. Os autores concluíram que em ambas as regiões a religiosidade está relacionada com a fecundidade. Na Europa, apesar de algumas limitações dos dados, as diferenças de filiação religiosa, pelo menos em termos de católicos e protestantes, podem explicar um pouco a variação dos níveis de fecundidade nestes dois grupos. Já nos EUA, as denominações mais "liberais", como presbiterianos, metodistas, luteranos e episcopais têm menor fecundidade quando comparados com católicos e protestantes fundamentalistas. Supondo que o nível de religiosidade entre os europeus fosse igual ao dos americanos os autores mostram que a fecundidade da Europa iria aumentar em torno de 14\%, mas mais consideravelmente para a Europa Ocidental (30\%). 
No Brasil, McKinnon et al. (2008), estudando adolescentes no Rio de Janeiro em 2000 encontraram que as chances de nunca ter tido um filho nascido vivo para mulheres jovens pertencentes a Batista, Protestante, Assembléia de Deus, Pentecostal e outras Igrejas protestantes era cerca de um terço a menos do que para as jovens católicas. Uma exceção ocorreu para as mulheres da Igreja Universal do Reino de Deus, na qual as adolescentes apresentaram uma fecundidade muito superior à das católicas. Os autores mostraram que esta fecundidade na adolescência elevada entre as protestantes esta muito relacionada à maiores chances das protestantes em casarem mais cedo do que as católicas.

Outro estudo que buscou entender a influência da religião na fecundidade foi Miranda-Ribeiro et al. (2009), o qual analisou a fecundidade na adolescência em Belo Horizonte e encontrou que a moda da curva foi distinta para as diferentes denominações religiosas. Entre as protestantes históricas, o padrão de fecundidade foi mais jovem e com o pico entre os 20 e 24 anos, ao passo que, para as sem religião e católicas, a moda se dá no grupo qüinqüenal seguinte. As pentecostais apresentaram padrão e nível da fecundidade bastante distintos das mulheres de outras religiões com elevado nível da fecundidade até os 29 anos.

Verona, Dias Junior (2012) também estudaram a relação entre fecundidade de adolescentes e religião no Brasil com dados de 1996 e 2006 e verificaram que adolescentes protestantes, particularmente pentecostais, apresentam um risco reduzido de serem mães adolescentes e antes do casamento. Os autores mostram que este resultado não era esperado, já que o pentecostalismo predomina nos grupos populacionais menos favorecidos, com menor renda, educação e residentes nas áreas urbanas, onde também se concentra a fecundidade de adolescentes no Brasil. Neste estudo, a freqüência a cultos e cerimônias religiosas mostrou-se bastante relevante em 1996 pois a frequência aos cultos ou missas foi mais importante na explicação da idade ao primeiro filho do que a filiação religiosa em si. Já em 2006, o pertencimento a uma igreja pentecostal é predominante na explicação da idade ao primeiro filho na adolescência e antes do casamento, pois independente da frequência aos cultos, jovens de igrejas pentecostais apresentaram 
um risco muito inferior de terem filhos na adolescência e antes do casamento do que as católicas.

Apesar de todos estes estudos tentarem a relação entre religião e fecundidade, existem graves problemas de mensuração desta relação, o que torna difícil entender se a religião por se só tem quaisquer conseqüências para a fecundidade, ou se a relação religião-fecundidade é espúria. Isso decorre principalmente porque a maioria das fontes de dados são transversais, isto é, mostram a participação religiosa no momento da entrevista, contudo a fecundidade é medida retrospectivamente. Em conseqüência, não faz sentido analisar a relação entre a participação religiosa como uma variável independente e a fecundidade como uma variável dependente, pois o interesse teórico é no efeito da participação religiosa prévia para a reprodução e sobre a fecundidade subsequente. A não atenção para esses problemas de medição pode levar a conclusões errôneas sobre a relação entre fecundidade e afiliação religiosa. Assim, um modelo completo teria que incluir indicadores de participação religiosa antes do parto, bem como indicadores de outros fatores a priori (por exemplo, status socioeconômico) que provavelmente teriam resultados sobre a fecundidade e participação religiosa pósnatal. Assim, o uso de modelos estatísticos só podem fazer a medição de associações, em vez de causalidade. A solução ideal, é claro, seria abandonar os dados transversais e trabalhar com dados em painel, em que seria desejável seguir pessoas da juventude através de seus anos férteis, seguir a filiação religiosa e participação ao longo da vida, não só antes de engravidar mas também quando as crianças nascem, crescem, e saem de casa, contudo estes dados ainda são raros eno caso do Brasil inexistentes (Marcum, 1988; Philipov, Berghammer , 2007).

\section{Fonte de dados e metodologia}

A fim de responder as questões apresentadas foram utilizados os dados da Pesquisa Nacional de Demografia e Saúde da Mulher e da Criança de 2006 (PNDS). 
Esta teve como finalidade atualizar o conhecimento dos indicadores de saúde da mulher e de saúde da criança, seus diferenciais e determinantes.

A pesquisa foi realizada entre mulheres de 15 a 49 anos de idade, de todas as cinco regiões do Brasil, urbanas e rurais. Por fazer parte das pesquisas do tipo DHS, ela apresenta muitas variáveis com possibilidades de comparação internacional e questões específicas para cada país. Esta pesquisa possui ricas informações sobre a preferências e comportamento reprodutivo das mulheres, bem como variáveis de conversão, afiliação e frequência religiosa.

A PNDS é uma pesquisa domiciliar por amostragem probabilística complexa, obtida em dois estágios de seleção (setores censitários e domicílios particulares). Nesse sentido, seguindo a recomendação do relatório técnico da pesquisa, para incorporar as informações do plano amostral delineado foram utilizadas as variáveis cdoo2-Conglomerado, cdoo3-Estrato e XM999_Peso, que correspondem, respectivamente, à informação dos setores censitários, à informação do estrato (combinação entre as cinco grandes regiões e área urbana e rural) e o peso amostral de cada mulher entrevistada. Alguns softwares oferecem rotinas específicas para o tratamento de dados provenientes de amostras complexas, tendo sido utilizado, neste trabalho, o pacote estatístico SPSS, versão 19, que permite realizar tais análises por meio dos comandos Analyze-Complex sample -Prepare for Analysis [weight=fator de expansão da amostra], strata(variável de estratificação) clusters(unidade primária de estratificação).

Utilizando a base de dados disponível pelo Ministério da Saúde a qual é composta por pessoas e mulheres com um total de 56365 observações, filtrou-se somente aquelas observações relacionadas às mulheres entrevistadas (15575). As variáveis selecionadas para análise nestes estudo foram: religião atual, religião que foi criada, frequência a cultos e missas, pessoas ano mulher e número de filhos nascidos vivos. Para a análise do comportamento reprodutivo foram calculadas as Taxas Específicas de Fecundidade por idade e as Taxas de Fecundidade Total a partir da religião atual da mulher, estado de conversão e freqüência a atividades religiosas. 
A TFT foi calculada a partir das recomendações feitas por Rutstein, Rojas (2003), os quais possuem um guia para as estatísticas desse tipo (formato Demographic Health Survey). O diferencial desta metodologia, é que esta considera no denominador das TEFs as pessoas-ano mulher, respeitando a definição correta de taxa. Para o cálculo das TEFs foram necessárias as seguintes informações: idade da mulher da data da entrevista, idade da mulher ao ter o filho e o grupo etário qüinqüenal ao qual ela pertence, filhos nascidos vivos nos últimos 36 meses antes da pesquisa ${ }^{2}$ e a idade do filho na data da entrevista.

Para se chegar ao numerador (nascidos vivos dos últimos 36 meses de mulheres em idade $\mathrm{x}$ a $\mathrm{x}+\mathrm{n}$ ) e o denominador (mulheres em idade $\mathrm{x}$ a $\mathrm{x}+\mathrm{n}$ ) da TEF foram seguidos os seguintes passos:

- Encontrando o numerador (filhos nascidos vivos nos últimos 36 meses por grupo etário da mulher no momento do nascimento): Os nascimentos são tabulados de acordo com o período em que ocorreram e a idade da mãe no momento do nascimento. Esse período de nascimento é calculado a partir da diferença em meses entre a data da entrevista e a data de nascimento. Já a idade da mãe no momento do nascimento é dada pela diferença em meses entre a data de nascimento da criança e a data de nascimento da mãe. Essa diferença é então dividida por $60^{3}$ e truncada para números inteiros, afim de se obter os filhos originados de cada grupos etário das mães. Assim os nascimentos são tabulados por faixa etária de idade das mães.

- Encontrando o denominador (pessoas ano mulher por faixa etária): As mulheres-anos de exposição são calculadas a partir da soma do número de meses expostos na faixa etária de cinco anos durante o período de tempo dividido por 12. Uma mulher pode contribuir para a exposição em dois grupos etários de cinco anos durante o período de 36 meses, assim é necessário encontrar o número de meses

\footnotetext{
${ }^{2}$ Os autores recomendam o uso das informações nos últimos 36 meses antes da pesquisa, uma vez que se reduz os erros amostrais e ao mesmo tempo os dados se mantém recentes.

${ }^{3}$ Representa o número de meses em 5 anos, onde cindo anso é o tempo entre cada grupo etário da mãe.
} 
vividos pela mulher em cada um desses dois grupos etários. O grupo etário atual da mulher é determinado pela idade da mulher no final do período, e essa faixa etária, considerada atual, é calculada subtraindo-se a data de nascimento da mulher pela data da entrevista menos um4, dividindo essa diferença por 60 e truncando a um número inteiro. O número de meses de permanência no grupo etário atual é a diferença de meses entre a idade ao final do período de exposição (data da entrevista menos um mês) e o limite mínimo de idade do grupo etário mais um mês. Se o número de meses no grupo etário atual é menor do que a duração do período de tempo (36 meses), então a mulher possui tempo de exposição em ambos os grupos etários, no que ela pertence e naquele de faixa etária imediatamente inferior. A contribuição em meses no grupo etário anterior ao atual é encontrada por meio da subtração de 36 menos ao número de meses no grupo etário atual. Se o número de meses no grupo etário atual é maior ou igual à duração do período de tempo (ou seja, $\geq 36$ meses), então o tempo de exposição no grupo atual é total e com isso o tempo de exposição na faixa etária anterior é zero.

A partir do numerador e denominador por grupo etário, é possível calcular a Taxa de Específica de Fecundidade. O resultado é um taxa média durante o período de 36 meses, expressa como uma taxa anual. E a partir dela é possível então calcular a TFT, em que se soma as TEF e multiplica-se por 5.

\section{Resultados e Discussões}

Das mulheres entrevistadas entre 15 a 49 anos, 61,5\% eram católicas, 13,1\% eram protestantes tradicionais, $11,5 \%$ eram protestantes pentecostais, 8,0\% sem religião e 5,9\% de outras religiões, revelando que em 2006 a religião católica ainda predominava entre as mulheres brasileiras, seguindo a tendência dos dados encontrados em outros estudos. Analisando essa distribuição segundo a idade temse o Gráfico I. Nota-se que entre católicas e protestantes tradicionais não há grandes diferenciais por idade em que a proporção do grupo etário de 15 a 19 anos

\footnotetext{
${ }^{4}$ A diminuição de 1 é justamente utilizada a fim de encontrar valores inteiros para o número de meses vividos no grupo etário, uma vez que para a demografia os cálculos são feitos com base em valores exatos e não números com casas decimais.
} 
fica em tono de $17 \%$ e termina com o de 45 a 49 com 11\%. Para o grupo das pentecostais, o percentual das adolescentes é um pouco menor, em torno de 12\%, eleva-se entre os grupos de 20 até 34 e depois cai a proporção das mulheres mais velhas, tornando-se bastante similar com a proporção das católicas e protestantes tradicionais. Já entre as sem religião, é nítido o seu comportamento diferenciado por idade, em que a maioria delas se encontram nos grupos mais jovens, especialmente de 20 a 24 , o qual concentra mais de $26 \%$ das fiéis, e somando as mulheres de até 30 anos, elas representam $67 \%$ das mulheres que se declaram sem religião.

Gráfico I - Distribuição percentual de mulheres por religião e idade, Brasil 2006.

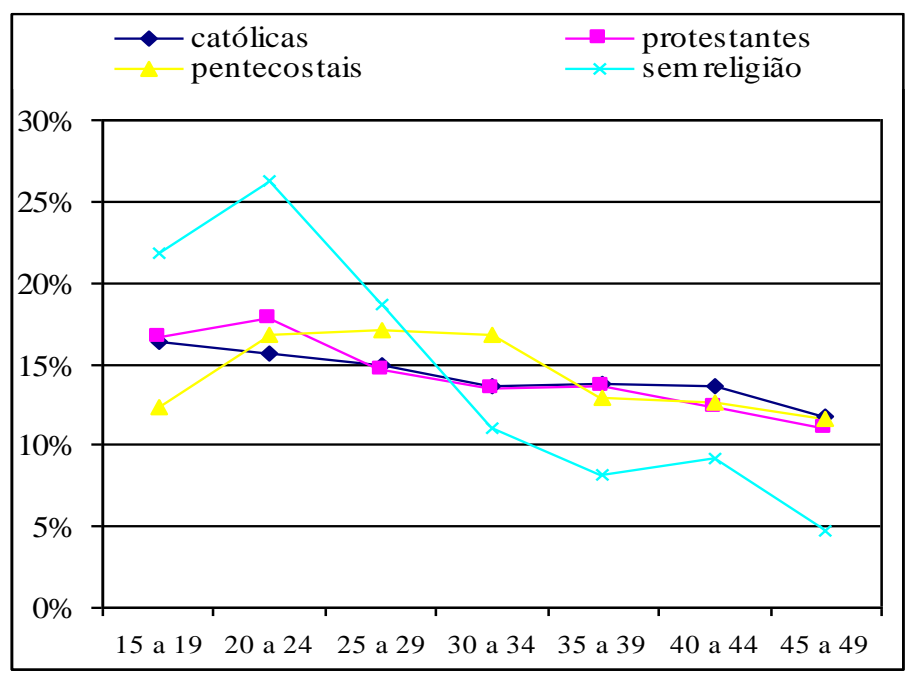

Fonte: Microdados PNDS, 2006

Sabendo que as mulheres em cada grupo religioso possui uma estrutura etária diferente, especialmente entre as sem religião, os resultados a seguir são meramente descritivos e não tem nenhuma pretensão de inferir causalidade entre religião e níveis de fecundidade. A fim de identificar possíveis diferenças, calculouse as Taxas Específicas de Fecundidade e a Taxa de Fecundidade Total por religião. Obteve-se uma TFT para o Brasil de 1,8 filhos mulher, sendo que a maior TFT foi encontrada entre as mulheres pentecostais (1,90 filhos por mulher), seguido das mulheres protestantes tradicionais em que a TFT foi de 1,88 e entre aquelas 
declaradas sem religião 1,83. Já entre as católicas a TFT ficou bastante reduzida (1,4 filhos por mulher).

Apesar destes dados não estarem controlados por demais variáveis de confusão estes resultados corroboram os achados do estudo feito por Carvalho et al. (2012) o qual, também com os dados da PNDS contudo utilizando-se das informações sobre parturição (número médio de filhos nascidos vivos), aplicou um modelo de regressão de Poisson em que foi possível controlar os efeitos de outras variáveis de contexto e revelou que mulheres evangélicas e sem religião apresentavam maiores chances de terem mais filhos nascidos vivos quando comparados com as mulheres católicas. Estas por sua vez, eram mais prováveis de terem menor parturição do que as mulheres de outras religiões.

Ainda observando o Gráfico II, percebe-se que os grupos religiosos possuem uma distribuição de fecundidade bastante distinto. As mulheres sem religião, bem como as protestantes apresentam uma fecundidade na adolescência e até os 24 anos bastante elevada. Entre as protestantes tradicionais nota-se uma curva mais espaçada, indicando que essas mulheres adiam mais os nascimentos, pois as TEF nas idades entre 25 e 34 são relativamente elevadas em relação aos demais grupos. Por outro lado, as mulheres católicas apresentaram a menor taxa de fecundidade na adolescência.

Gráfico II - Taxas Específica de Fecundidade e Taxa de Fecundidade Total segundo religião, Brasil 2006.

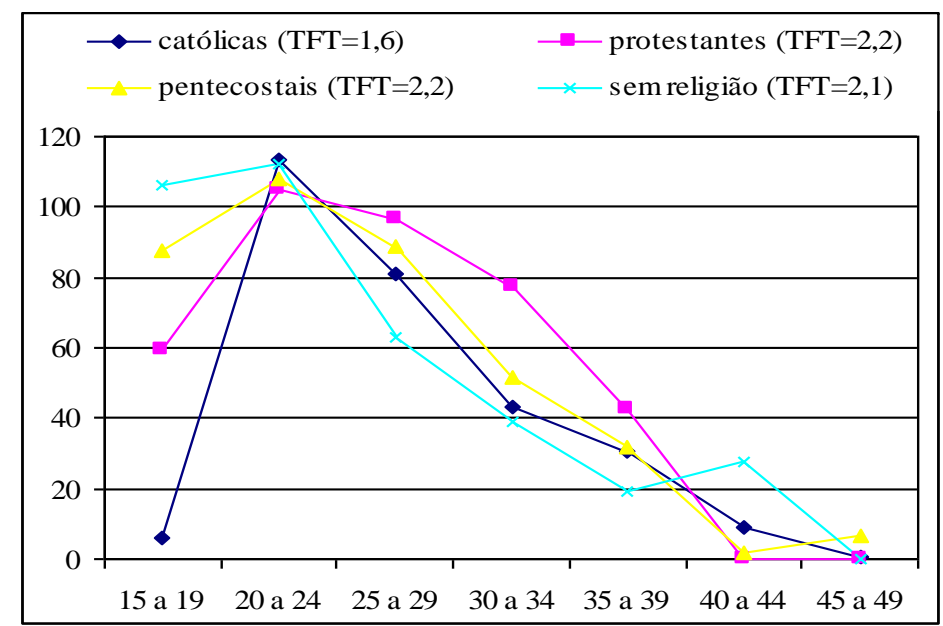

Fonte: Microdados PNDS, 2006 
Perante as mudanças no cenário religioso do Brasil é importante entender o papel da conversão a fim visualizar melhor as diferenças de fecundidade entre os grupos religiosos. Pois é necessário observar se o fato de sempre participar5 de uma mesma religião leva a níveis e padrões diferentes de fecundidade. Com esse intuito então, analisou-se os dados sobre a religião em que foi criada e a religião atual. Pôde-se notar que das mulheres entrevistadas, 26\% não possuem a mesma religião a qual foram criadas, ou seja, se converteram pelo menos uma vez. Destas, mais de $50 \%$ se declaram atualmente protestantes pentecostais e tradicionais $(26,8 \%$ e 26,6\%respectivamente), $26,3 \%$ não possuíam religião atualmente, $15 \%$ eram de outras religiões e apenas $5 \%$ eram católicas. Isso mostra que a maioria das mulheres católicas possui a mesma religião em que foram criadas. Reforçando esses achados e analisando por uma outra ótica, a Tabela I revela que das mulheres em idade reprodutiva entrevistadas que se declararam católicas, apenas $2,2 \%$ não foram criadas nesta religião, enquanto que entre as pentecostais esse percentual é de $60,4 \%$, entre as protestantes tradicionais isso representava $52,8 \%$ e as entre as de outras religiões $69,8 \%$. Contudo percebe-se que é entre aquelas mulheres que se declararam sem religião que acontece maior migração de classificação religiosa, pois $86,7 \%$ delas não foram criadas como pessoas sem religião, mostrando que possivelmente estas mulheres já se classificaram anteriormente como fiéis de alguma religião. Isso de alguma forma reforça a ideia de secularização da sociedade brasileira.

\footnotetext{
${ }^{5}$ Estamos assumindo que as mulheres nunca converteram, mas não é necessariamente verdade, pois elas podem ter nascido em uma religião, se converteram a outra e depois retornaram para a religião em que foram criadas. Estas migrações entre as religiões não são captadas na pesquisa.
} 
Tabela I - Distribuição percentual das mulheres segundo religião atual e religião em que foram criadas, Brasil 2006.

\begin{tabular}{|c|c|c|c|c|c|c|}
\hline \multirow[b]{2}{*}{ Religião em que foi criada } & \multicolumn{5}{|c|}{ Religião atual } & \multirow[b]{2}{*}{ Total } \\
\hline & Católica & Protestante & Pentecostal & $\begin{array}{c}\text { Sem } \\
\text { religião }\end{array}$ & $\begin{array}{c}\text { Outra } \\
\text { s }\end{array}$ & \\
\hline Católica & 97,85 & 47,95 & 52,83 & 50,55 & 62,51 & 80,32 \\
\hline Protestante & 1,08 & 47,17 & 3,09 & 18,33 & 2,42 & 8,81 \\
\hline Protestante & 0,68 & 1,78 & 39,57 & 14,59 & 0,32 & 6,41 \\
\hline Sem religião & 0,12 & 2,77 & 3,65 & 13,32 & 3,91 & 2,14 \\
\hline Outras & 0,26 & 0,33 & 0,86 & 3,20 & 30,85 & 2,32 \\
\hline
\end{tabular}

Fonte: Microdados PNDS 2006

Com relação à conversão e idade, observa-se no Gráfico III que entre as mulheres atualmente católicas, parece não haver mudança de acordo com a idade, em que para todos os grupos mais de 95\% delas continuam na mesma religião. Já para as protestantes tradicionais, pentecostais e de outras religiões, observa-se que tende a cair o percentual daquelas mulheres que possuem a mesma religião em que foram criadas, mostrando que possivelmente estas mulheres aderiram a essas religiões ao longo de suas vidas, chegando no último grupo etário em que apenas $33 \%$ e $20 \%$ foram criadas na religião protestante e pentecostal respectivamente. Como esperado, aquelas mulheres atualmente sem religião, são as que menos declaram pertencer à religião em que foram criadas. Esses achados reforçam a idéia de que as pessoas mudam sua opção religiosa ao longo de suas vidas especialmente para as religiões protestantes.

Gráfico III - Distribuição percentual das mulheres que nunca se converteram segundo religião atual e idade, Brasil 2006.

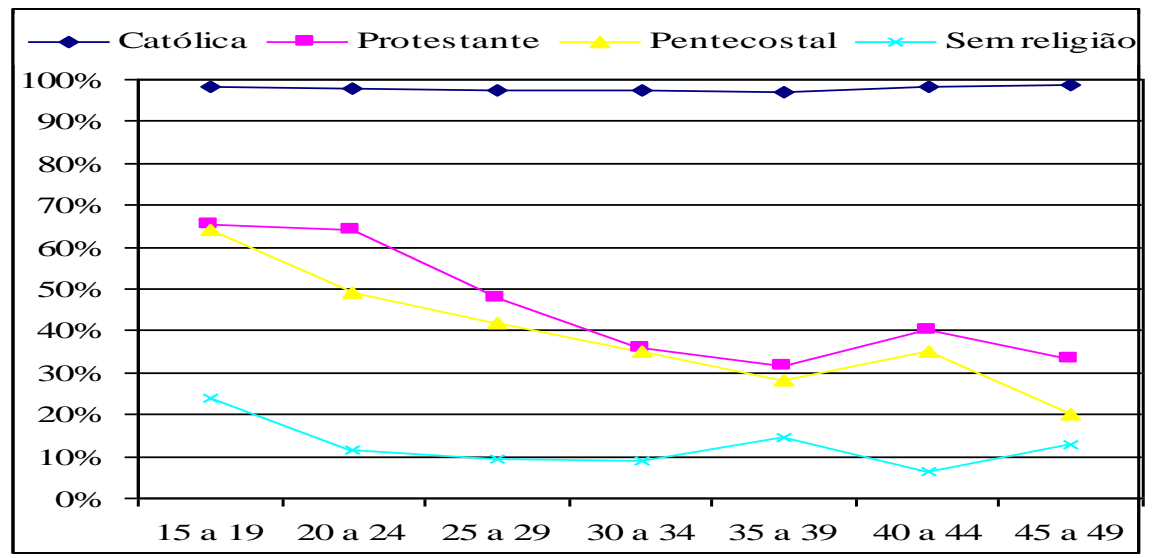

Fonte: Microdados PNDS, 2006 
Analisando a Tabela II a qual mostra as TEF e a TFT segundo a religião atual da mulher e conversão, nota-se que de modo geral as mulheres que nunca se converteram possuem menor fecundidade do que aquelas que se converteram. Este resultado pode estar relacionado ao fato de que a maioria das mulheres que nunca se converteram serem católicas e estas apresentam baixa fecundidade na adolescência (Gráfico II). Observa-se ainda que entre as católicas, as pentecostais e sem religião a TFT é maior para aquelas que têm a mesma religião em que foi criada do que para aquelas que trocaram de religião. Por outro lado para mulheres protestantes tradicionais a TFT para aquelas que nunca ser converteram é menor do que para aquelas que trocaram de religião ao longo da vida. Com relação à conversão e idade, não se observou um padrão claro de comportamento reprodutivo e devido à falta de casos para alguns grupos religiosos optou-se por não apresentar os resultados.

Tabela II - Taxa de Fecundidade Total segundo religião atual e conversão, Brasil 2006

\begin{tabular}{ccc}
\hline religião atual & Nunca converteu & Converteu \\
\hline católica & 1,43 & 1,15 \\
protestante & 1,73 & 2,04 \\
protestante pentecostal & 1,87 & 1,84 \\
sem religião & 2,36 & 1,82 \\
Total & 1,42 & 1,84 \\
\hline
\end{tabular}

Fonte: Microdados PNDS, 2006

Na Tabela III tem-se a distribuição das mulheres segundo frequência à cultos e cerimônias religiosas, idade e religião atual. Os dados mostram que as pentecostais e protestantes tradicionais eram as que mais relataram participar de atividades religiosas, pois estas apresentavam uma frequência assídua de 76,4\% e 80\% respectivamente), contrariamente nesta categoria eram apenas $34,2 \%$ das católicas. Destas a maioria (50,9\%) frequentavam pouco, enquanto que entre as protestantes esse percentual era de $21,0 \%$ e $17,4 \%$ para a protestantes tradicionais e 
pentecostais respectivamente. Esses dados reforçam a teoria de que no Brasil, a maior participação nas atividades religiões se dá entre os protestantes, especialmente os pentecostais. Como esperado entre o grupo das sem religião, a maioria $(68,8 \%)$ não frequentam, contudo é interessante observar que nesse grupo que os outros 31,2\% mostraram alguma forma de frequência, indicando que apesar da declaração elas possuem algum tipo de religiosidade e por isso acabam freqüentando alguma atividade religiosa.

Ainda na Tabela III, analisando a participação e a idade das mulheres, observa-se que entre o grupo das mulheres que possuem uma alta frequência, as mais velhas possuem maior percentual de participação do que as mais jovens para todas as religiões. Por exemplo, entre protestantes tradicionais $70 \%$ das mulheres de 15 a 19 disseram frequentar assiduamente enquanto que entre as mulheres de 45 a 49 esse percentual sobe para $88 \%$. Surpreendentemente também aumenta com a idade o percentual daquelas pentecostais que dizem não frequentar atividades religiosas (2\% entre 15 a 19 e $7 \%$ entre 45 a 49 anos). Entre o grupo das sem religião, as mulheres de 45 a 49 são aquelas que mais disseram não frequentar (76\% delas). Esses achados corroboram com o estudo de Hayford, Morgan (2008) que estudaram a importância da religião nos Estados Unidos e encontraram que a importância relatada de religião, também está associada a fatores sóciodemográficos, principalmente idade, pois a proporção de mulheres que sentem que a religião é muito importante para eles aumenta de $43 \%$ das entre as mulheres de 15-19 para 58\% das mulheres dos 40-44 anos. 
Tabela III - Distribuição percentual das mulheres por frequência a cultos e cerimônias religiosas segundo idade e religião atual, Brasil, 2006

\begin{tabular}{|c|c|c|c|c|c|c|c|c|}
\hline Frequência & 15 a 19 & $\begin{array}{c}20 \mathrm{a} \\
24\end{array}$ & $\begin{array}{c}25 \mathbf{a} \\
29\end{array}$ & $\begin{array}{c}30 \mathbf{a} \\
34\end{array}$ & $\begin{array}{c}35 \mathbf{a} \\
39\end{array}$ & $\begin{array}{c}40 \mathrm{a} \\
44\end{array}$ & $\begin{array}{c}45 a \\
49\end{array}$ & Total \\
\hline \multicolumn{9}{|c|}{ Católica } \\
\hline $\begin{array}{c}\text { Frequenta } \\
\text { assiduamente* }\end{array}$ & 32,52 & 28,72 & 32,33 & 31,60 & 36,56 & 37,07 & 42,68 & 34,22 \\
\hline Frequenta pouco ${ }^{* *}$ & 53,04 & 49,23 & 52,75 & 53,56 & 52,91 & 48,73 & 45,96 & 50,93 \\
\hline Não frequenta & 14,44 & 22,04 & 14,91 & 14,84 & 10,52 & 14,20 & 11,36 & 14,84 \\
\hline Total & 100,00 & 100,00 & 100,00 & 100,00 & 100,00 & 100,00 & 100,00 & 100,00 \\
\hline \multicolumn{9}{|c|}{ Protestante } \\
\hline $\begin{array}{c}\text { Frequenta } \\
\text { assiduamente* }\end{array}$ & 70,38 & 72,65 & 75,92 & 74,64 & 80,00 & 77,78 & 87,61 & 76,41 \\
\hline Frequenta pouco ${ }^{* *}$ & 28,74 & 22,10 & 22,07 & 22,83 & 19,29 & 19,05 & 9,29 & 21,05 \\
\hline Não frequenta & 0,88 & 5,25 & 2,01 & 2,54 & 0,71 & 3,17 & 3,10 & 2,55 \\
\hline Total & 100 & 100 & 100 & 100 & 100 & 100 & 100 & 100 \\
\hline \multicolumn{9}{|c|}{ Protestante pentecostal } \\
\hline $\begin{array}{c}\text { Frequenta } \\
\text { assiduamente* }\end{array}$ & 79,19 & 76,74 & 74,68 & 76,90 & 86,70 & 84,51 & 85,58 & 80,00 \\
\hline Frequenta pouco ${ }^{* *}$ & 18,55 & 22,59 & 21,75 & 20,46 & 10,73 & 15,04 & 7,69 & 17,39 \\
\hline Não frequenta & 2,26 & 0,66 & 3,57 & 2,64 & 2,58 & 0,44 & 6,73 & 2,61 \\
\hline Total & 100 & 100 & 100 & 100 & 100 & 100 & 100 & 100 \\
\hline \multicolumn{9}{|c|}{ * Frequenta assiduamente (1 vez ou mais por semana) } \\
\hline \multicolumn{9}{|c|}{${ }^{* *}$ Frequenta pouco ( 3 vezes ou menos ao mês) } \\
\hline \multicolumn{9}{|c|}{ Fonte: Microdados PNDS, 2006} \\
\hline
\end{tabular}

Analisando o comportamento reprodutivo e a frequência a cultos e cerimônias religiosas, tem-se no Gráfico IV abaixo que, independente da religião atual da mulher, aquelas que declaram frequentar assiduamente apresentaram menor TFT e menor fecundidade na adolescência em relação aquelas mulheres que declaram baixa frequência à atividades religiosas (TFT de 1,59 filhos por mulher). Surpreendentemente, foi o grupo das mulheres que declararam participar 3 vezes ou menos ao mês que obtiveram a maior TFT (1,99 filhos por mulher). Por outro lado, foram as mulheres que declaram não participar de atividades religiosas que 
apresentaram as mais elevadas TEF na adolescência. Esses achados corroboram a idéia discutida por Anuatti-Neto, Narita (2004) de que mulheres com mais filhos têm menos tempo de ir a igreja, ou seja, a adesão religiosa pode refletir um problema de alocação de tempo das mulheres, que devem destinar parte de seu tempo na dedicação aos filhos, principalmente na fase em que eles ainda não estão na escola.

\section{Gráfico IV - Taxas Específicas de Fecundidade segundo religião atual e frequência a atividades religiosas, Brasil 2006}

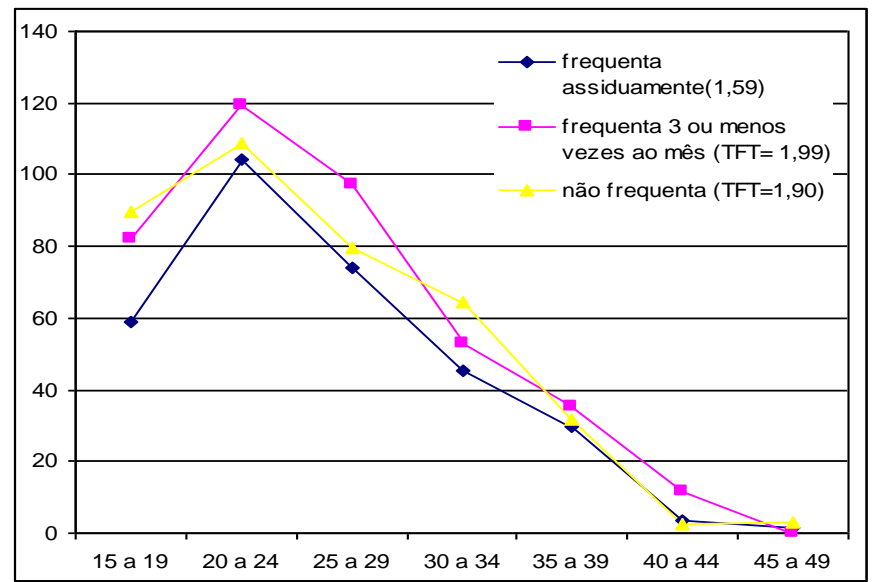

Fonte: Microdados PNDS, 2006

A Tabela IV mostra a TFT por freqüência religiosa e religião atual da mulher, pode-se observar que entre católicas e protestantes a TFT é menor para aquelas mulheres que relataram freqüentar assiduamente atividades religiosas. Interessante observar que foi entre o grupo que respondeu freqüentar pouco (3 vezes ou menos por semana) onde a TFT foi maior para todas as religiões. Como dito anteriormente, provavelmente pode ser um efeito de causalidade, uma vez que as mulheres que tem maior número de filhos acabam por ter menos disponibilidade para freqüentar a Igreja (Anuatti-Neto, Narita, 2004). Além disso, pode-se associar esses achados com as discussões feitas por Philipov, Bergammer (2007) que analisaram o impacto da religião em ideais, intenções e comportamento, a influência da religião é mais pronunciada nos ideais de fecundidade do que nas intenções e no comportamento. Segundo os autores isso se justifica a partir das interações significativas que existem entre o sistema social 
religioso e os outros sistemas. Assim religião não toma uma posição hierárquica entre os sistemas sociais onde fecundidade é considerado.

\section{Tabela IV - Taxa de Fecundidade Total por religião segundo} participação em cultos e cerimônias religiosas, Brasil 2006

\begin{tabular}{cccc}
\hline Religião atual & $\begin{array}{c}\text { Frequenta } \\
\text { assiduamente }\end{array}$ & $\begin{array}{c}\text { Frequenta } \\
\text { pouco }\end{array}$ & $\begin{array}{c}\text { Não } \\
\text { frequenta }\end{array}$ \\
\hline Católica & 1,36 & 1,98 & 1,87 \\
Protestante & 1,87 & 2,06 & 1,90 \\
Pentecostal & 1,81 & 2,10 & 2,03 \\
\hline
\end{tabular}

* Frequenta assiduamente (1 vez ou mais por semana)

**Frequenta pouco (3 vezes ou menos ao mês)

Fonte: Microdados PNDS, 2006

Com relação às taxas de fecundidade específicas por idade, notou-se no Gráfico V que entre as protestantes pentecostais que frequentam assiduamente, a estrutura da fecundidade é mais rejuvenescida, pois as TEFs são mais elevadas no grupo de 15 a 20 anos e no 20 a 24, em relação às católicas e protestantes tradicionais. O pico de fecundidade é de 20 a 24 anos para as três religiões estudas, destacando o grupo das mulheres protestantes tradicionais, pois apresenta uma concentração da fecundidade importante também nos grupos acima de 30 anos. Ao analisar o grupo das mulheres que freqüentam pouco, percebe-se que o comportamento reprodutivo para esse grupo de mulheres é bastante heterogêneo segundo a religião atual desta. Nota-se que, contrariamente ao grupo das mulheres que frequentam assiduamente, as católicas lideram a fecundidade no grupo de 15 a 19 anos. Por outro lado, a fecundidade na adolescência é pequena para o grupo das protestantes tradicionais. Agora o pico de fecundidade se dá no grupo etário de 25 a 29 anos para as protestantes e permanece aos 20 a 24 para católicas. Esses achados seguem a tendência encontrada por Zanata (2011), em que dentre os diversos fatores encontrados associados ao aumento da chance de iniciação sexual 
precoce está o fato de ser menos religioso ou frequentar pouco a igreja, e com isso tem-se aumentadas as chances de ocorrência de nascimentos. ${ }^{6}$

\section{Gráfico V - Taxas de Específicas de Fecundidade para mulheres que frequentam assiduamente cultos e cerimônias religiosas por religião atual, Brasil 2006}
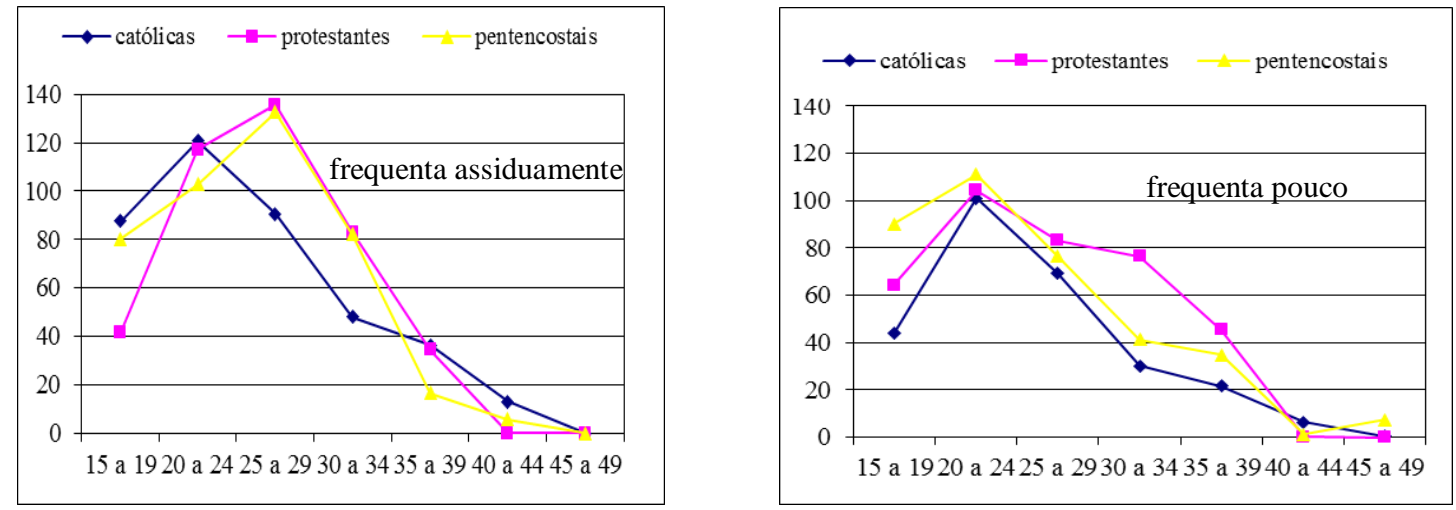

Fonte: Microdados PNDS, 2006

\section{Considerações Finais}

Muitas mudanças têm ocorrido no comportamento reprodutivo das mulheres brasileiras. Concomitantemente, a religião vem ganhando destaque neste campo de pesquisa, uma vez que tem-se constatado sua importância sobre a vida dos indivíduos, inclusive sobre o comportamento e as escolhas reprodutiva das mulheres. Pois sabe-se que as igrejas e comunidades são bem sucedidas na criação de mecanismos indiretos por meio dos quais a religião pode influenciar o comportamento demográfico dos seus fiéis.

O objetivo principal deste artigo foi fazer uma descrição das Taxas Específicas de Fecundidade e da Taxa de Fecundidade Total das mulheres brasileiras segundo religião, conversão e freqüência a cultos e cerimônias religiosas. A partir desses achados, tentou-se identificar possíveis diferenciais por

\footnotetext{
${ }^{6}$ Devido a problemas amostrais optou-se por não apresentar os dados por idade para as mulheres que não freqüentam atividades religiosas.
} 
religião fazendo uma conexão entre as várias teorias que mostram como a religião pode influenciar os níveis e padrões de fecundidade.

Os dados sugerem que realmente existem diferenciais nas taxas de fecundidade segundo religião. As católicas apresentaram uma fecundidade bastante reduzida e muito inferior às protestantes. As mulheres sem religião, ao contrário do esperado não apresentaram a maior TFT, ficando esta para as mulheres declaradas protestantes tradicionais.

Quanto aos diferenciais a partir da conversão, pôde-se concluir que possuir uma mesma religião ao longo da vida para católicas, pentecostais e sem religião fez com que estas obtivessem uma TFT maior do que aquelas que trocaram de religião. Por outro lado entre as protestantes tradicionais a TFT foi menor para aquelas que possuíam a mesma religião em que foram criadas em comparação com aquelas que trocaram de religião. Teve-se também que tanto para as católicas quanto para as protestantes pentecostais a estrutura de fecundidade foi mais rejuvenescida para aquelas mulheres que declararam não ter a mesma religião em que foram criadas. O mesmo não foi observado para as mulheres sem religião e protestantes tradicionais, as quais pelo contrário, em que aquelas convertidas apresentaram uma estrutura de fecundidade mais envelhecida.

Por fim, os dados sobre frequência religiosa, são pouco conclusivos, pois são influenciados por um problema metodológico, o efeito de causalidade. Pois ter uma menor fecundidade pode ter contribuído para uma maior participação à atividades religiosas, pois por um lado, as mulheres que têm menos filhos teoricamente tem mais tempo para se dedicar à outras atividades, tal como participação em cerimônias religiosas. Por outro lado, pode ser que devido à reduzida ou nenhuma participação em atividades religiosas e consequentemente pouca influência das doutrinas e ensinamentos da igreja no comportamento reprodutivo, estas mulheres acabaram apresentando maior fecundidade. Um fato interessante foi que frequentar pouco aumentou a TFT para todas religiões, sugerindo que não são os 
extremos de participação que possuem maior impacto para os diferencias na fecundidade, mas provavelmente que é a situação de transição/adaptação, ou o popularmente comportamento conhecido como "ficar em cima do muro" em que a mulher não adota e nem rejeita completamente os ensinamentos da religião acaba por deixa-las mais exposta ao risco de ter filhos.

Pode-se concluir que a fecundidade das mulheres se diferencia a partir da sua escolha religiosa e o fato de possuir a mesma religião ou não ao longo da vida e o tipo de participação que se tem nas atividades da igreja pode resultar em comportamentos reprodutivos diferenciados ao longo da vida das fiéis. $\mathrm{O}$ que pode indicar a influência dos ensinamentos e costumes religiosos sobre mais um dos componentes demográfico.

Contudo vale ressaltar que estas estimativas podem estar sendo influenciadas pelo efeito de composição presentes nesses grupos religiosos, tais como educação e renda. E assim, podem existir outros fatores que também contribuam para tais diferenças. Independentemente disso, este foi um primeiro esforço, no intuito de compreender melhor a relação da religião sobre um dos componentes da dinâmica demográfica, a fecundidade. Sabendo das limitações deste estudo e das intrigantes relações que ainda podem ser desvendadas, fazem-se necessárias outras pesquisas que envolvam essa temática. Este artigo centrou-se sobre a medição das TEF e TFT por religião, e possíveis diferenças quanto à conversão e freqüência. No entanto, tem-se um vasto campo dentro da temática comportamento reprodutivo e sexual a ser pesquisado, como por exemplo, o uso de contraceptivos, a satisfação com o número de filhos, questões de gênero nas decisões sobre a vida reprodutiva do casal, dentre outros. 


\section{REFERÊNCIAS}

ADSERA, A. Marital fertility and religion in Spain, 1985 and 1999. Population Studies, Britain, v. 60, n.2, p. 205-221, 2006a.

ADSERA, A. Religion and changes in family-size norms in developed countries. Review of Religious Research, Galva, v. 47, n.3, p. 271-286, 2006b.

ALVES, J. E. D. Transição da fecundidade e relações de gênero no Brasil. 1994. 152f. Tese (Doutorado) - Centro de Desenvolvimento e Planejamento Regional, Universidade Federal de Minas Gerais, Belo Horizonte, 1994

ALVES, J.E.D. O processo de mudança de hegemonia religiosa no Brasil. (versão preliminar. 2012. Disponível em: < <http://www.ie.ufrj.br/aparte/pdfs/a_mudanca_de_hegemonia_religiosa_no_brasil_02 abr12.pdf > . Acesso em: 06 jul. 2012.

ALVES , J. E. D.; NOVELLINO , M. S. A dinâmica das filiações religiosas no Rio de Janeiro: 1991-2000 - um recorte por educação, cor, geração e gênero. In: PATARRA, N.; AJARA, C.; SOUTO, J. O Rio de Janeiro continua sendo... Rio de Janeiro: Ence/IBGE, 2006. p. 275-308.

ANTONIAZZI, A. Por que o panorama religioso no Brasil mudou tanto? São Paulo: Paulus, 2006.

ANUATTI-NETO, F.; NARITA, R. D. T. A Influência da opção religiosa na acumulação de Capital Humano: Um Estudo Exploratório. Estudos de Economia, São Paulo, v. 34, n. 3, p. 453-486, Julho-Setembro 2004.

BERQUÓ, E.; CAVENAGHI, S. M. Mapeamento sócio-econômico e demográfico dos regimes de fecundidade no Brasil e sua variação entre 1991 e 2000. In: ENCONTRO NACIONAL DE ESTUDOS POPULACIONAIS, 14. Anais... Caxambu: ABEP, 2004.

CARVALHO, A. A.; GUERRA, F. F.; DIAS, I. G. Análise dos determinantes da fecundidade desejada: uma abordagem comparativa a partir dos determinantes do número de filhos de tidos. In: Congresso da Associação Latino-americana de População, 5. Anais... Montevidéu: ALAP, 2012

DECOL, R. D. Mudança religiosa no Brasil: uma visão demográfica. Revista Brasileira de Estudos de População, Rio de Janeiro, v. 16, n. 1/2, p. 121-137, 1999.

ELLISON, C. G.; LEVIN, J. S. The religionhealth connection: evidence, theory, and future directions. Health Education Behavior, New York, v. 25, p. 700-720, 1998.

FREJKA, T.; WESTOFF, C.F. Religion, religiousness and fertility in the US and in Europe. European Journal of Population, Netherlands v. 24, n.1, p. 5-31, 2008. 
HAMMEL, E.A. A theory of culture for demography. Population and Development Review. New York, v. 16 n. 3, p. 455-485, 1990.

HAYFORD, S. R.; MORGAM, S.P. Religiosity and Fertility in the United States: The Role of Fertility Intentions. Soc Forces, Chapel Hill, v. 86, n. 3, p. 1163-1188, 2008.

HEILBORN, M. L.; BARROS, M. L.; DUARTE, L. F. D. Família e religião. Rio de Janeiro: Contra Capa, 2007.

INSTITUTO BRASILEIRO DE GEOGRAFIA E ESTATÍSTICA - IBGE. Tendências demográficas: uma análise da população com base nos resultados dos censos demográficos 1940 e 2000. Rio de Janeiro: IBGE. Disponível em: < http://www.ibge.gov.br/home/estatistica/populacao/tendencia_demografica/analise_pop ulacao/1940_2000/analise_populacao.pdf >. Acesso em: 06 jul. 2012.

LEVITT, P. You know Abrahan was really the first immigrant:religion ad transtational migration. International Migration Review, New York, v. 37, n. 3; p. 847-873, 2003.

MACHADO, M. das D. C. Adesão religiosa e seus efeitos na esfera privada - um estudo comparativo dos carismáticos e pentecostais do Rio de Janeiro. 1994. Tese (Doutorado) IUPERJ, Rio de Janeiro.

MCKINNON, S.; POTTER , J.; GARRARD-BURNETT , V. Adolescent fertility and religion in Rio de Janeiro, Brazil in the year 2000: the role of Protestantism. Population Studies, Britain, v. 62, n. 3, p. 289-303, 2008.

MCQUILLAN, K. When does religion influence fertility? Population and Development Review, London, v. 30, n. 1, p. 25-56, 2004.

MARCUM, J. P.Religious Affiliation, Participation and Fertility: A Cautionary. Journal for the Scientific Study of Religion, Indianapolis, v. 27, n. 4, p. 621-629, 1988.

MIRANDA-RIBEIRO, P.; LONGO, L. A. F. B.; RIOS-NETO, E. L. G.; POTTER, J. E. Fecundidade na adolescência e religião em Belo Horizonte: um primeiro exercício. Revista Brasileira de Estudos de População, Rio de Janeiro, v. 26, n. 2, p. 305-308, 2009.

PHILIPOV, D.; BERGHAMMER, C. Religion and fertility ideals, intentions and behaviour: a comparative study of European countries. Vienna Yearbook of Population Research, Vienna, p. 271-305, 2007.

PIERUCCI, A. F. O.; PRANDI, R. Religious diversity in Brazil: numbers and perspectives in a sociological evaluation. International Sociology, Sydney, 15, p. 629-639, 2000.

PNDS. Pesquisa Nacional de Demografia e Saúde da Mulher e da Criança. Disponível em: <http://bvsms.saude.gov.br/bvs/pnds/index.php>. Acesso em: 20 maio 2012.

RUTSTEIN, S. O.; ROJAS, G. Guide to DHS statistics. Calverton: ORC Macro, 2003. 
VERONA, A. P. A. Sexual initiation and religion in Brazil.2010. Tese (Doutorado em Sociologia). University of Texas at Austin.

VERONA, A. P. A.; HUMMER, R.; DIAS JUNIOR, C. S.; LIMA, L. Infant mortality and mothers' religious involvement in Brazil. Revista Brasileira de Estudos de População, Rio de Janeiro, v. 27, n. 1, p. 59-74, 2010.

VERONA, A. P. A. Explanations for religious influence on adolescent sexual behavior in Brazil: direct and indirect effects. Revista Brasileira de Estudos de População, Rio de Janeiro, v. 28, n. 1, p. 187-201, 2011.

VERONA, A. P. A.;DIAS JÚNIOR C. S. Religião e fecundidade entre adolescentes no Brasil. Rev. Panam. Salud. Publica, Danvers, v. 31, n. 1, p. 25-31, 2012.

ZANATA, R. C. A carne é fraca: religião, religiosidade e iniciação sexual entre estudantes do Ensino Médio na Região Metropolitana de Belo Horizonte, 2008. Dissertação (Mestrado em Demografia), Universidade Federal de Minas Gerais, Belo Horizonte.

WOOD, C.; WILLIAMS, P.; CHIJIWA, K. Protestantism and child mortality in Northeast Brazil, 2000. Journal for the Scientific Study of Religion, Indianapolis, v. 46, n. 3, p. 405-416, 2007. 